\title{
脊䯣・脳幹部の拡散強調画像における PSIF法，SPLICE法の有用性
}

\author{
打越将人・植田隆史・楫靖1）・过 昭夫・和田昭彦・今岡いずみ \\ 松尾導昌・丸山克也2) ・岡本 淳 ${ }^{2)}$ ・滝沢 修 ${ }^{2}$ \\ 天理よろづ相談所病院放射線部MR部門 \\ 1 ) 神戸大学医学部放射線科 \\ 2)シ一メンス旭メディテック株式会社
}

Code No. 261

緒 言

拡散強調画像は，急性期脳梗塞やその他中枢神経系 診断において有用性が確立されている。しかし，一般
的に用いられているEPI (echo planar imaging)法では, 金髅や脳幹部など磁化率効果の影響の強い部位におけ る評洒は困難なことをしばしば経験する。近年EPI法

\section{Diffusion MR Imaging with PSIF and SPLICE: Experiences in Phantom Studies and the Central Nervous System}

\section{MASATO UCHIKOSHI, TAKASHI UEDA, YASUSHI KAJI, ")AKIO TSUJI, AKIHIKO WADA, IZUMI IMAOKA, MICHIMASA MATSUO, KATSUYA MARUYAMA, 2) JUN OKAMOTO, ${ }^{2)}$ and OSAMU TAKIZAWA2)}

MR Division, Department of Radiology, Tenri Hospital

1 ) Department of Radiology, Kobe University School of Medicine

2) Siemens-Asahi Medical Technologies Ltd.

Received Jan. 18, 2001; Revision accepted March 23, 2001; Code No. 261

\section{Summary}

Studies have shown that diffusion MR imaging is a reliable method for the diagnosis of central nervous system diseases, especially acute cerebral infarction. Although echo planar imaging(EPI) is a promising tool for that purpose, it is vulnerable to susceptibility artifacts that are responsible for image distortion or signal loss. Our purpose in this study was to evaluate the usefulness of diffusion MR imaging with PSIF (reversed fast imaging SSFP) and split acquisition of fast-spin-echo signals for diffusion imaging (SPLICE) in the central nervous system (CNS). First, PSIF and SPLICE were applied to the phantoms. Each phantom, including acetone, acetic acid, and water, was analyzed for ADC based on SPLICE and for diffusionrelated coefficient (DRC) based on PSIF. The ADCs based on SPLICE were $4.36 \pm 0.89 * 10^{-3} \mathrm{~mm}^{2} / \mathrm{sec}, 1.25 \pm 0.04$ $* 10^{-3} \mathrm{~mm}^{2} / \mathrm{sec}$, and $2.35 \pm 0.04 * 10^{-3} \mathrm{~mm}^{2} / \mathrm{sec}$, and the DRCs based on PSIF were 0.353 $\pm 0.25,0.178 \pm 0.07$, and $0.273 \pm 0.018$ for acetone, acetic acid, and water, respectively. These calculated ADCs based on SPLICE were well correlated with known diffusion coefficients, showing a correlation coefficient of 0.995. Second, PSIF and SPLICE were applied to the CNS. The advantage of PSIF and SPLICE was that susceptibility artifacts were reduced in the images of spinal cord and brain stem. PSIF was especially useful for diffusion MR imaging in the spinal cord. The disadvantage of SPLICE was the decreased SN ratio. We conclude that PSIF or SPLICE may be helpful when EPI diffusion MR imaging is insufficient.

Key words: Spinal cord, Diffusion-weighted image (DWI), Diffusion weighted-reversed fast imaging SSFP(DWPSIF), Split acquisition of fast-spin-echo signals for diffusion imaging (SPLICE) 


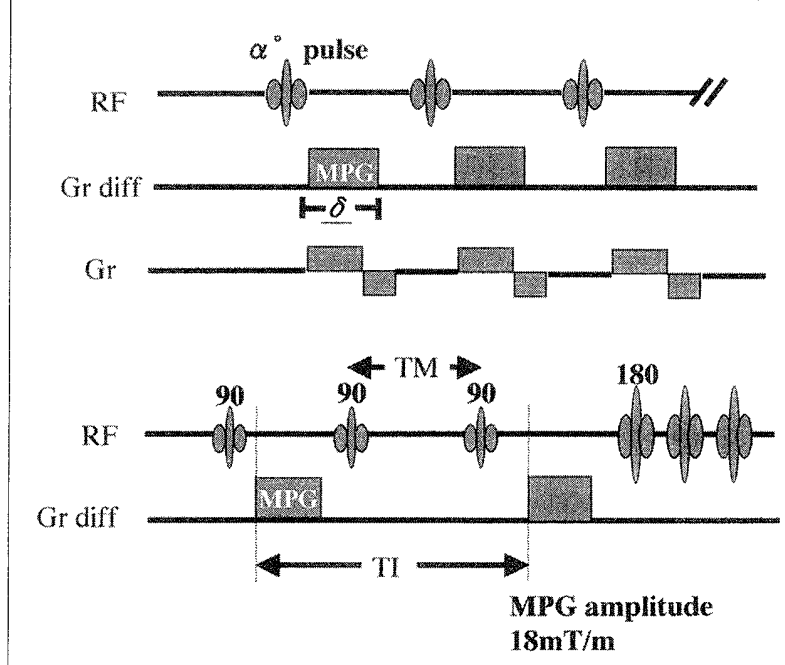

Fig. 1 (a) DW-PSIF sequence timing chart. (b) SPLICE sequence timing chart.

で描出困難な部位に対し，磁化率効果の影響を比較的 受けにくいSSFP (steady state free precession) 系 ${ }^{1 \sim 6)}$ や SSTSE (single shot turbo spin echo) ${ }^{7)}$ を利用した拡散 強調画像が報告されている。 今回, PSIF (reversed fast imaging-SSFP) 法にMPG (motion-probing-gradient) パ ルスを印加したDW-PSIF法，およびSSTSEにMPGパ ルスを印加したSPLICE (split acquisition of fast-spinecho signals for diffusion imaging) 法8)を用いた拡散強 調画像について検討したので報告する。

\section{1. 方 法}

使用装置は，SIEMENS社製MAGNETOM Vision 1.5T VB33A，用いたコイルはCP (circular polarized) headおよびCP-neck array，CP-spine array coilである。 パルス系列はSE型DW (diffusion weighted)-EPI法, DW-PSIF法，SPLICE法を用いた。DW-PSIF法， SPLICE法のタイミングチャートをFig.1に，撮像条件 をTable 1に示す。なお，DW-PSIF法はb 值を計算で きないため, MPGの印加時間 $(\delta)$ を変化させ，拡散の 強調度を調節した。

\section{1-1 ファントムによる検討}

DW-PSIF法，SPLICE法掞よびDW-EPI法にて，三 種類の自作ファントム (acetone：99.5\%溶液, acetic acid：17.5mol/1水溶液, water) を, Table 1 に示すよう にb-factorおよび $\delta$ 変化させ撮像した。 MPGパルスは phase encode方向， slice selective方向，read out方向 にそれぞれ印加した。得られた各ファントム画像に ROI (region of interest) を設定し，その信号強度を測定

した。DW-PSIFでは, ADC (apparent diffusion coefficient）を求めることができないため，得られた值 を指数関数で近似し，その係数をdiffusion related coefficient（DRC）と定義した，SPLICE，DW-EPIについ てはADCを計算し，DRCおよびADCと各ファントム 固有の拡散係数 (D-values) ${ }^{1)}$ と比較した。

\section{1-2 臨床応用}

対象は筒䯣に疾患が㲛われた13症例，脳幹部に疾患 が疑われた 2 症例である。 $\mathrm{T}_{2}$ 強調像 $(\mathrm{TR} / \mathrm{TEef}=4000 /$ $120 \mathrm{~ms}$ ) で指摘された病巣部を含むスライスを選択 L, 全例でDW-EPI法 $(\mathrm{TR} / \mathrm{TE}=4000 / 100 \mathrm{~ms}$, 加算回数 1 回, matrix $96 \times 128$, 撮像時間 $32 \mathrm{~s}, \mathrm{~b}$-factor $=0$, $500,1000) に て$ 撮像した。次いでDW-PSIF法 $\left(\mathrm{TR}=30 \mathrm{~ms}\right.$, FA $50^{\circ}$ ，加算回数 5 回，matrix $256 \times 256$, 撮像時間 $29 \mathrm{~s}, \delta=0,3,5,7,11)$ は春䯣 $12 / 13$ 症例, 脳幹部1/2症例に, SPLICE法 (TE $81 \mathrm{~ms}, F A ~ 180^{\circ}$ ，加 算回数 5 回, matrix $128 \times 256$, 撮像時間 $26 \mathrm{~s}, \mathrm{~b}$ factor $=0,303,655,772)$ は春髄8/13症例，脳幹部2/

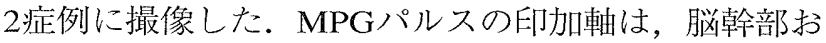
よび脊髄の神経線維束に沿った頭尾方向( read out J 向）に印加した。それぞれの拡散強調画像から下記の 式により rADC (relative apparent diffusion coefficient), $\mathrm{ADC}^{9)}$ を計算した。

DW-PSIF法のrADC : $D=\ln (S 0 / S 1)$

SPLICE法のADC $: D=\ln (S 0 / S 1) /(b 1-b 0)$

\section{2. 結 果}

\section{2-1 ファントムによる検討}

各シーケンスについて, Fig. 2にb-factorに対する信 号強度変化を示す(ファントム自体，MPGパルスの印 加軸方向に依存しないため read out方向に印加した信 号強度のみプロットした). b-factorを大きくするに従 って, DW-EPI法, DW-PSIF法㧍よびSPLICE法すべ てのシーケンスに扮いて同じように信号が減衰してい ることが分かる。Fig. 3にADC, DRCとD-valueとの 関係を示す。acetone, acetic acid, waterのADCは, DW-EPI法では4.52, $1.14,2.35 \times 10^{-3} \mathrm{~mm}^{2} / \mathrm{sec}$, SPLICE法では4.36， $1.25 ， 2.52 \times 10^{-3} \mathrm{~mm}^{2} / \mathrm{sec}$ となりDvaluesとは差買はなかった $(\mathrm{p}<0.006)$. DW-PSIFにつ いては，前述したようにDRCとして算出しており， 数值を直接比較することはできないが DRCとD-values とは高い相関（相関係数 $\mathrm{r}=0.963$ )が得られた。

\section{2-2 臨床応用}

脊髄病巣において，T2WIで高信号を呈する病巣を 描出できたのは，DW-EPI法で0例，DW-PSIF法で11/ 
Table 1 Parameters of diffusion weighted imaging.

\begin{tabular}{cccccc}
\hline & $\mathrm{b}$-factor $\left(\mathrm{s} / \mathrm{mm}^{2}\right)$ & $\delta(\mathrm{ms})$ & $\mathrm{TR}(\mathrm{ms})$ & $\mathrm{TE}(\mathrm{ms})$ & Matrix size \\
\hline DW-EPI & $0 \sim 1100$ & - & 4000 & 100 & $96 \times 128$ \\
DW-PSIF & - & $0 \sim 12$ & 30 & - & $256 \times 256$ \\
SPLICE & $0 \sim 772$ & - & - & 80 & $128 \times 256$ \\
\hline
\end{tabular}
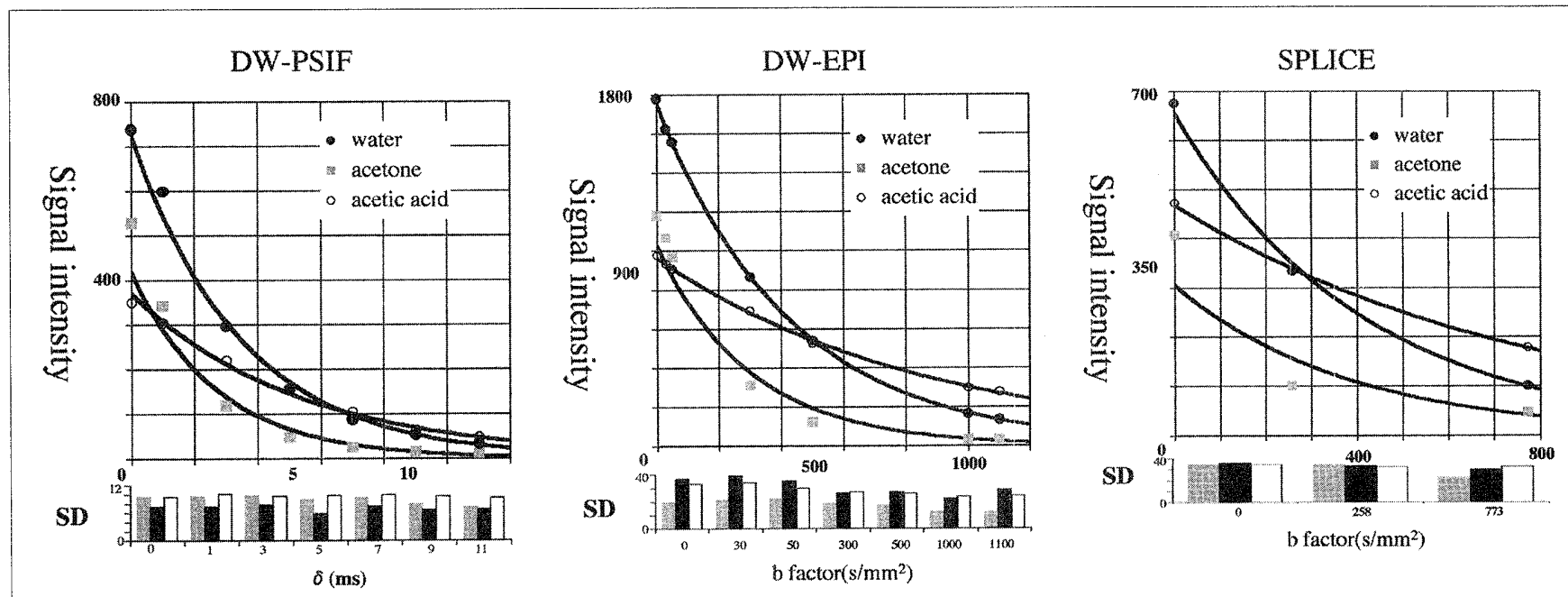

Fig. 2 (a) ROI intensity values in phantom as a function of DW-PSIF $(\delta)$

(b) ROI intensity values in phantom as a function of DW-EPI (b-factor).

(c) ROI intensity values in phantom as a function of SPLICE (b-factor).

12例，SPLICE法で2/8例であった．脳幹部病巣 2 例 は，全撮像法で描出できたがDW-EPI法では，アーチ ファクト様にも考元られる画像を呈した。脊髄病巣部 の範囲は，DW-PSIF法でT 2 WIの高信号より狭く描出 されたのが9/11例，同等か少し広く描出されたのが2/ 11 例, 脳幹部では狭く描出された. SPLICE法では, 脳幹部病巣は2/2例でT 2 WIでの高信号域より広く描出 されたが，脊髄においてはほとんどの症例で病巣部の 検出が困難であった。

rADC，ADCは，脳幹部病巣では患者の状態によ $\eta$ ，複数のb-factor， $\delta$ を撮像できず，算出できなかっ た。春髄病巣について, DW-PSIF法では11例全例 (Table 2)でrADCの差異を認めた。またCSFのrADCは $3.40 \pm 0.12$, 正常脊䯙道は $1.66 \pm 0.20$ となった. SPLICE法 では， case 5 において $\mathrm{ADC}_{\text {lesion }}=1.7 \times 10^{-3}$, $\mathrm{ADC}_{\text {normal }}$ $=1.6 \times 10^{-3} \mathrm{~mm}^{2} / \mathrm{sec}$ となり差異はなかったが, case6は $\mathrm{ADC}_{\text {lesion }}=2.7 \times 10^{-3}, \mathrm{ADC}$ normal $=1.5 \times 10^{-3} \mathrm{~mm}^{2} / \mathrm{sec}$ と各 $\mathrm{ADC}$ 差異を認めた。

Fig. 4〜6に臨床例を示す.

\section{3. 考 察}

仚䯣・脳幹部は，頭部に比べて非常に磁化率の異な った構造物で形成されているため，拡散強調画像を撮 像する際にEPI法を基本とするシーケンスでは評価困 難な場合が多かった。この問題を克服するため，近年 さまざまなシーケンスによる拡散強調画像が報告され ているが，臨床応用するに際し，基礎的な拡散能を把 握し，臨床適応について検討しておくことは重要であ る10 13)。そこで今回われわれはDW-PSIF法, SPLICE 法について基礎的な検討を行い，次に臨床応用を試み た。

（1）DW-PSIF法のDRCは，各ファントムのD-values と異なった值を示すため，定量的に評価すること はできない。しかし，DRCとD-valuesは高い相関 関係を示していることから，定性的な拡散強調画 像としての応用は十分可能であると考える。一 方, SPLICEのADCは, D-valuesとの差も僅か で，定量的評価も行えると推測する。

(2) 臨床へ応用した結果，春髄や脳幹部に扮いて DW-PSIF法, SPLICE法では, DW-EPI法と比較 

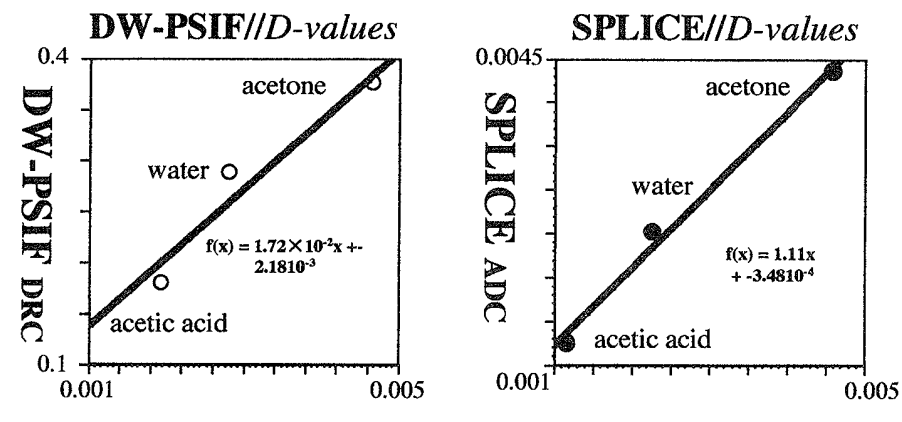

D-values $\left(\mathrm{mm}^{2} / \mathrm{s}\right)$

\begin{tabular}{ccccc} 
& $\begin{array}{c}\text { DW-PSIF } \\
\text { DRC }\end{array}$ & $\begin{array}{c}\text { DW-EPI } \\
\text { ADC }\end{array}$ & $\begin{array}{c}\text { SPLICE } \\
\text { ADC }\end{array}$ & D-values \\
\hline acetone & $3.53 \pm 0.25$ & $4.52 \pm 0.10$ & $4.36 \pm 0.89$ & 4.58 \\
acetic acid & $1.78 \pm 0.07$ & $1.14 \pm 0.03$ & $1.25 \pm 0.04$ & 1.16 \\
water & $2.73 \pm 0.18$ & $2.35 \pm 0.04$ & $2.52 \pm 0.17$ & 2.26 \\
\cline { 2 - 5 } Correlation coefficient & 0.963 & 0.974 & 0.995 &
\end{tabular}

ADC, D-values: Mean $\pm \mathrm{SD} \times 10^{-3} \mathrm{~mm}^{2} / \mathrm{s}$ DRC: Mean \pm SD $\times 10^{-1}$

Fig. 3 (a) Correlation between D-value and DRC in DWPSIF, and D-value and ADC in SPLICE sequence. (b) Calculated $A D C$ and $D R C$ versus $D$ values.
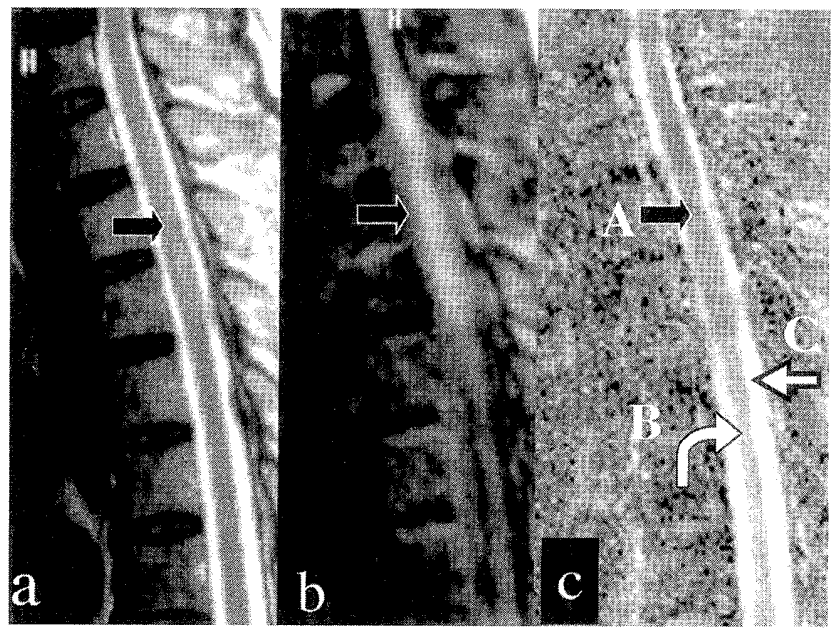

Fig. 4 A 53-year-old woman with herpes-associated myelopathy.

(a) $\mathrm{T}_{2}$-weighted sagittal image shows a hyperintense lesion at the TH3-5 level (black arrow).

(b) DW-PSIF image [ $\delta=7]$ demonstrates the hyperintense lesion more clearly than the $\mathrm{T}_{2}$ weighted image (black arrow).

(c) rADC image shows a hypointense lesion corresponding to the hyperintense lesion on the DW-PSIF image, with ADC of $0.71 \times 10^{-1} \mathrm{~mm}^{2 /}$ $s$ (arrow A).

*Arrow $B$ is normal spinal cord with $A D C$ of $1.84 \times 10^{-1} \mathrm{~mm}^{2} / \mathrm{s}$. Arrow $\mathrm{C}$ is CSF with ADC of $3.20 \times 10^{-1} \mathrm{~mm}^{2} / \mathrm{s}$ a
Table 2 rADCs of legion, normal and CSF by DW-PSIF.

\begin{tabular}{lccc}
\hline \multicolumn{1}{c}{ Case } & Lesion & Normal & CSF \\
\hline 1. Abscess & 1.15 & 1.51 & 3.42 \\
2. Infarction & 1.49 & 1.92 & 3.45 \\
3. Syringomyelia & 3.07 & 1.66 & 3.52 \\
4. Helpes myelitis & 0.71 & 1.84 & 3.20 \\
5. Multipul sclerosis & 1.52 & 1.64 & 3.41 \\
6. Central duct & 2.86 & 1.37 & 3.45 \\
7. Multipul sclerosis & 1.20 & 1.74 & 3.18 \\
8. Spondylosis & 0.82 & 1.56 & 2.82 \\
9. Spondylosis & 1.02 & 1.77 & 3.65 \\
10. Spondylosis & 0.95 & 1.45 & 3.22 \\
11. Spondylosis & 1.15 & 1.68 & 3.28 \\
\hline
\end{tabular}

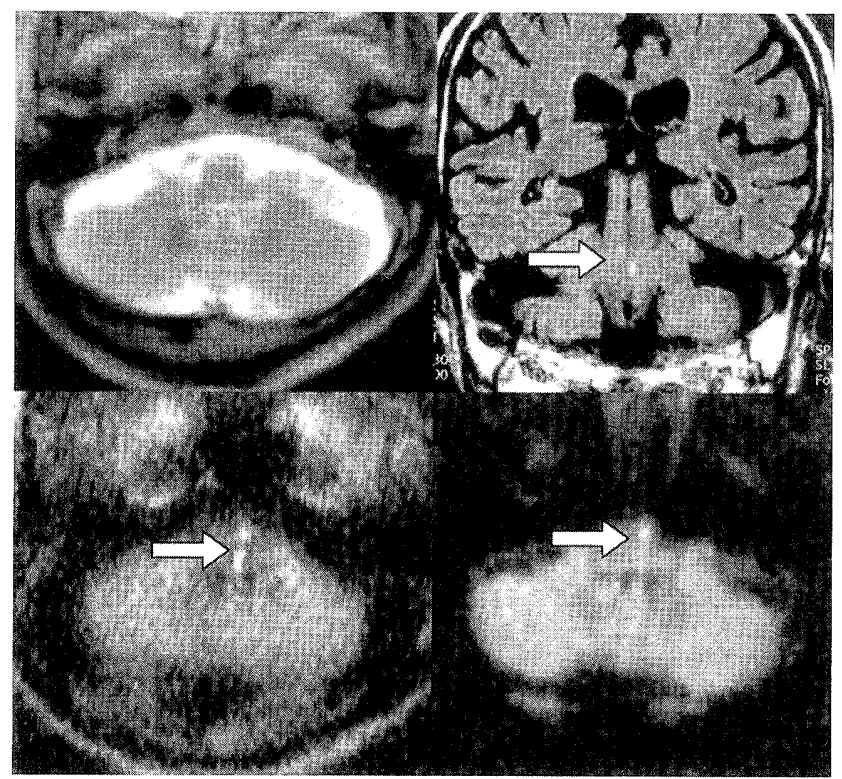

Fig. 5 An 81-year-old man with Wallenberg syndrome.

(a) No area of abnormal intensity was identified on the $T_{2}$-weighted axial image.

(b) On the FLAIR coronal image, two high-intensity lesions (white arrow) are seen at the medulla oblongata.

(c) On the SPLICE $\left(b=772 \mathrm{~s} / \mathrm{mm}^{2}\right)$ image, two highintensity spots (white arrow) are seen at the lateral side of the medulla oblongata.

(d) One of the two high-intensity spots is recognized on the DW-EPI image $\left(b=1000 \mathrm{~s} / \mathrm{mm}^{2}\right)$. 
してアーチファクトの少ない画像が得られた。し かし, SPLICE法は10症例中 4 症例しか病巣を描 出できなかった。この原因としてSPLICE法の画 像を構成している信号がS/Nの劣るstimulated echoを用いているため，特に病巣が小さい場合に 評価困難となったものと考える。将来spin echoを 利用したシーケンスが開発されてくればS/Nの改 善が期待できる。一方，DW-PSIF法では13症例 中11症例で病巣を描出できた。描出できなかっ た2症例は，いずれもlaminectomy後の春䯣病巣 であり，PSIF法がグラディエントエコーを利用 していることにより，手術操作による金属片の混 入などの影響と考えられる。しかし脊髄病巣の検 出に関して最もアーチファクトが少なく，今回定 義したrADCの算出によって，T2 shine throughの 影響を除去した，病巣の拡散をとらえられるシー ケンスであると考える。またDW-EPI法の利用不 可能な対象での拡散強調画像においてDW-PSIF 法の普及およびspin echo法を利用したSPLICE法 の開発が望まれる。

\section{5. 結 語}

脳幹部および脊髄など，磁化率効果による影響を受 けやすい部位に対してのDW-PSIF法,SPLICE法を用い た拡散強調画像は有用であった。

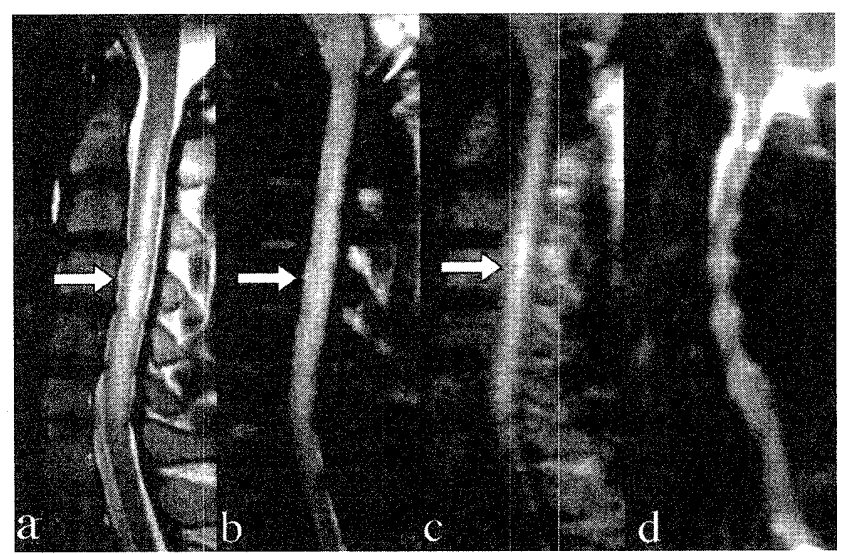

Fig. 6 A 30-year-old woman with relapsed multiple sclerosis.

(a) $\mathrm{T}_{2}$-weighted sagittal image shows abnormal hyperintensity at the level of $\mathrm{C} 2-\mathrm{C} 6$ (white arrow).

(b) DW-PSIF $[\delta=5 \mathrm{msec}]$.

(c) SPLICE $\left[\mathrm{b}=655 \mathrm{~s} / \mathrm{mm}^{2}\right]$.

Both DW-PSIF and SPLICE images demonstrated the hyperintense lesion as smaller than the $T_{2}$-weighted image did. This might suggest that new MS plaques were identified on DW PSIF and SPLICE images, whereas the hyperintense lesion on $T_{2}$-weighted imaging included both the chronic lesion and new plaques.

(d) DW-EPI $\left[\mathrm{b}=0 \mathrm{~s} / \mathrm{mm}^{2}\right]$.

本論文の要旨は，第56総会学術大会 $(2000$ 年 4 月， 横浜)で発表した。

\section{参考文献}

1) Zur Y, Bosak E, and Kaplan N: A new diffusion SSFP imaging technique. MRM, 37, 716-722, (1997).

2) Ding $S$, Trillaud $H$, Yongbi $M$, et al.: High resolution renal diffusion imaging using a modified steady-state free precession sequence. MRM, 34, 586-595, (1995).

3) Patersson JS and Christoffersson JO: A multidimensional partition analysis of SSFP image pulse sequence. MR Image, 15 (4), 451-467, (1997).

4) Bruning R, Wu RH, Deimling M, et al.: Diffusion measuremants in the ischemic human brain with a steady-state sequence. Invest Radiol, 31 (11), 709-715, (1996).

5) Gudbjartsson H and Patz S: Simultaneous calculation of flow and diffusion sensitivity in stead-state free precession imaging. MRM, 34 (4), 567-579, (1995).

6) Carney CE, Wong ST, and Patz S: Analytical and verificant of diffusion effect in SSFP. MRM, 19(2), 240-246, (1991).

7) Lovblad KO, Jakob PM, Chen Q, et al.: Turbo spin-echo diffsion-weighted MR of ischemic stroke. AJNR Am J Neuroradiol, 19 (2), 201-208, (1998).
8) Schick F: SPLICE; Sub-second diffusion-sensitive MR imaging using a modified fast spin-echo acquisition mode. MRM, $38,638-644,(1997)$.

9）錦 成郎，小蒼明夫，川光秀昭，他：MR撮像技術一よりよ い画像を得るために一。放射線医療技術学裳書 (18), pp. 37-41，54-58，73-76，121-123，通商産業研究社，東京， (2000).

10）山田晴耕，大久保敏之，阿部 修：MRにおける拡散のす

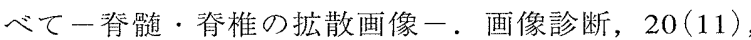
1255-1258, (2000).

11) Holder CA: MR diffusion imaging of the cervical spine. MRI CLINICS OF NORTH AMERICA, 8 (3), 675-686, (2000).

12) Schwartz ED, Yezierski RP, Pattany PM, et al.: Diffusionweighted MR imaging in a rat model of syringomyelia after excitotoxic spinal cord injury. AJNR, 20 (8), 1422-1428, (1999).

13) Chad A, Muthupillai R, and Mukundan S: Diffusion-weighted MR imaging of the normal human spinal cord in vivo. AJNR Am J Neuroradiol, 21, 1799-1806, (2000). 


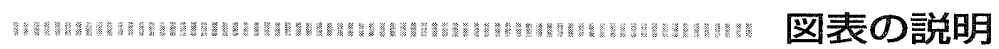

Fig. 1 (a)DW-PSIF法のタイミングチャート.

(b)SPLICE法のタイミングチャート.

Fig. 2 (a)DW-PSIF法における拡散強調度に対する信号強度変化.

(b)DW-EPI法における拡散強調度に対する信号強度変化.

(c) SPLICE法における拡散強調度に対する信号強度変化.

Fig. 3 (a) 各シーケンスのDRC，ADCに対するファントム固有の㕬散係数.

(b) DRC，ADCとD-valuesの比較，相関係数.

Fig. 4 胸髄のヘルペス春髄炎に抢ける拡散強調画像.

(a) $\mathrm{T}_{2}$ 矢状断像の胸髄 $3 〜 5$ レベル $($ 黑 $\rightarrow)$ に高信号を呈する满変部を示す.

(b) $\delta$ を $7 \mathrm{~ms}$ に変化したDW-PSIF画像では，T2強調画像より病变部(黑 $\rightarrow$ )がより鮮明に描出されている.

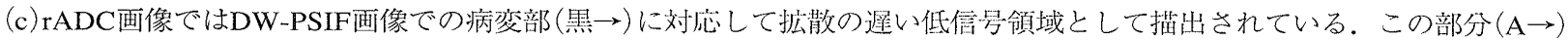
のrADCは $0.71 \times 10^{-1} \mathrm{~mm}^{2} / \mathrm{s}$ で正常部 $(\mathrm{B} \rightarrow)$ の $\mathrm{rADC}$ of $1.84 \times 10^{-1} \mathrm{~mm}^{2} / \mathrm{s}$ り低いことが分かる. CSF $(\mathrm{C} \rightarrow)$ の $\mathrm{rADC}$ $3.20 \times 10^{-1} \mathrm{~mm}^{2} / \mathrm{s}$.

Fig. 5 ヴアレンベルク症候群に扔ける拡散強調画像.

(a) $\mathrm{T}_{2}$ 横断像では病変部を示す様な異常信号は確認できない.

(b)FLAIR冠状断では延䯣に二つ点状の高信号を是する。

(c) SPLICE (b factor $\left.=772 \mathrm{~s} / \mathrm{mm}^{2}\right)$. 点状の高信号は延髄外側に描出されている.

(d) DW-EPI (b factor=1,000 $\left./ \mathrm{mm}^{2}\right)$ では 2 点のうち 1 点しか諗識できない.

Fig. 6 多発性硬化症の再発に扔ける拡散強調画像.

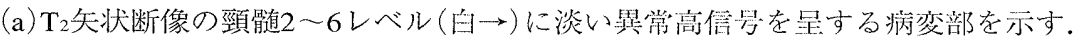

(b) DW-PSIF ( $\delta=5 \mathrm{msec})$.

(c) SPLICE $\left(\mathrm{b}=655 \mathrm{~s} / \mathrm{mm}^{2}\right)$

両方法とも， $\mathrm{T}_{2}$ 強調画像での高信舁の範罒上り小さく描出された。それは，慢性，急性の脱髄帯が混在する $\mathrm{T}_{2}$ 強調画像 のなかで，DW-PSIFやSPLICEで描出された高信号は急性期の多発性硬化症脱髄帶を示していると考えられた。

(d) DW-EPI $\left(\mathrm{b}=0 \mathrm{~s} / \mathrm{mm}^{2}\right)$

Table 1 MPGパルスの強さおよびその他撮像条件.

Table 2 㝑髄病変のDW-PSIFで得られた, 病変部, 正常部, CSFのrADC. 